\title{
Jejunal Polyps that Lead to Small Bowel Intussusception in Adults:
}

\author{
A Rare Case Report \\ Shahid Nazir, Ambreen Munir, Sehrish Sulman, Qazi Waleed-u-Zaman, \\ Aisha Yar Muhammad
}

\begin{abstract}
Small intestine polyps are very rare in adults. Incidental finding of those polyps; sending them for histopathology that comes out to be Peutz-Jeghers syndrome (PJS) is extremely rare. PJS is an inherited disease characterized with typical hamartomas polyps in intestine along with distinctive skin pattern and mucocutaneous pigmentation. Gene mutation is responsible for $93 \%$ of PJS cases, among which majority of cases occur due to mutation in STK11 gene.

PJS patients have 15-fold higher risk of developing cancer, including intestinal, extra-intestinal, breast, lung, pancreatic and colorectal cancer. Although PJS incidence is very low but its early recognition is very important for lowering morbidity and mortality. In this study, we have reported a very rare case of PJS in adults that was operated for small bowel obstruction secondary to intussusception. These cases are very rare in literature.
\end{abstract}

Key words: Peutz-Jeghers syndrome, Hamartomas polyps, Mucocutaneous pigmentation, Gene mutation.

\begin{abstract}
This article may be cited as: Nazir S, Munir A, Sulman S, Waleed-u-Zaman Q, Muhammad AY. Shahid Nazir, Ambreen Munir, Sehrish Sulman, Qazi Waleed-u-Zaman, Aisha Yar Muhammad. J Liaquat Uni Med Health Sci. 2020;19(02):139-41. doi: 10.22442/jlumhs.201920677
\end{abstract}

\section{INTRODUCTION}

Polyps occur throughout the GI tract in Peutz-Jeghers syndrome and Small intestinal polyps are rare in adult and are usually a part of polyposis syndromes ${ }^{1}$. PeutzJeghers syndrome is extremely rare disease that is found as autosomal dominancy as a hereditary. It categorized by skin disorders mostly pigmented papules and macules along with gastrointestinal polyposis, the mainstream of which are hamar-tomas and mainly found in small bowl. It was just once a thought that patients suffering from Peutz-Jeghers syndrome, there is an extremely low frequency of the conversion of those hamartomas to malignant. Nevertheless, increasing literature is evident which shows that patients having Peutz-Jeghers syndrome are at a higher risk of conversion into malignant polyps, along with increased risk from benign to malignant tumours to be present in other body organs ${ }^{2}$. Therefore, cases of obstruction and intussusception reported due to occurrence of polyps in various parts of intestine has been rarely been reported.

\section{CASE REPORT}

A 26-Years male, electively admitted via OPD with complains of pain in abdomen from age of 12 years and lump felt at left side of abdomen for one month. $\mathrm{He}$ also had on and off episodes of vomiting for one month. He described pain as sudden bouts of colicky abdominal pain in periumbilical region more marked on left side of abdomen that lasted for 1-2 days. Pain was intermittent with symptom free intervals. Patient was stable and show no any significant improvement or worsening in condition. No evidence of shifting or radiation of pain. It was although associated with relative constipation and vomiting. Meanwhile a week ago patient observed the lump at left side of abdomen that was mildly tender, and size remain same before disappearance. No any lump was observed at the time of admission along with absence of any systemic illness or injury responsible for causing lumps. Systemic inquiry, past medical and surgical history was insignificant. There was no significant similar family history although his mother and father had Diabetes and Hypertension. On physical examination, hyperpigmented macules was observed on lips but not on fingers and toes tips Figure I. Abdominal examination was unremarkable at the time of examination. Laboratory inquiries shows the normal blood count along with normal liver and renal function. CT scan abdomen with contrast showed the telescoping of proximal small bowel loops into distal small bowel loops in mid of abdomen, extending from epigastrium up to the pelvis along with twisting of mesentery that is representing small bowel intussusception of with partial small bowel obstruction. He underwent planned laparotomy that revealed proximal section of jejunum, almost $20 \mathrm{~cm}$ apart from Treitz ligament, which was invaginated in distal jejunum, that finally confirm diagnosis of intussusception; another segment of jejunum almost $20 \mathrm{~cm}$ away from prior pathology was also involved as intussusception. Primary resection and anastomosis 
was done from ligament of Treitz almost up to proximal part of lleum. The whole resected segment revealed multiple polyps of variable sizes and specimen was sent for histopathology Figure II. After surgery patient completed the uneventful postoperative course of 10 days and discharged from the hospital. His final histopathology revealed jejunum filled up with multiple hamartomatous polyps of variable sizes but no evidence of high-grade dysplasia or invasive malignancy. Resected margins were unremarkable. Currently patient is stable and has returned to his daily life activities and he was being advised to follow up with large bowel colonoscopy to see any associated pathology.

\section{FIGURE I:}

\section{SHOWING PERIORAL HYPERPIGMENTATION}

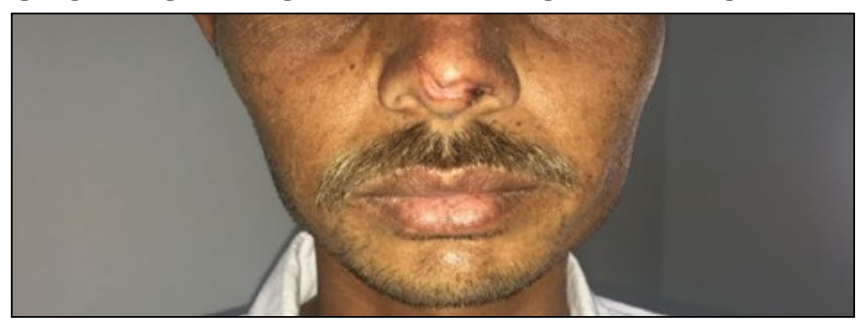

FIGURE II: MULTIPLE SIZE POLYPS OF RESECTED PORTION OF JEJUNUM

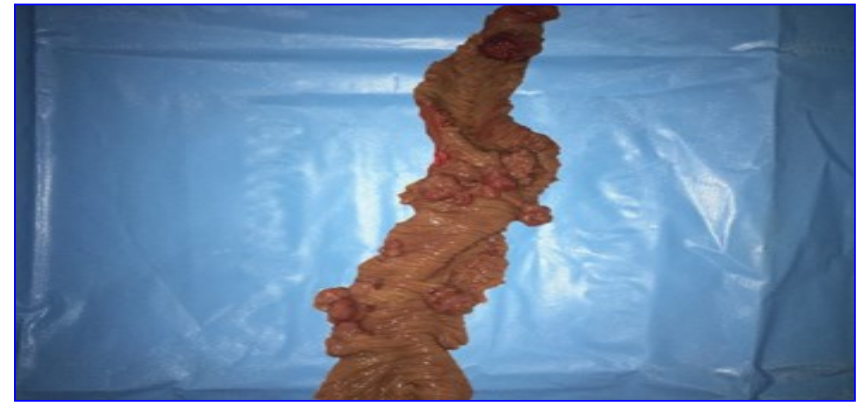

\section{DISCUSSION}

PJS is a rare congenital, autosomal dominant condition with inconstant heritage, categorized into hamartomatous polyps in digestive tract, typically in small bowel and in pigmented mucocutaneous lesions. In year 1895 Connor defines the PeutzJeghers syndrome in a pair of identical twins with melanotic macules that further demonstrated by Hutchinson in year $1896^{3,4}$. Later, in year 1921, welldefined by Peutz followed by Jeghers in year 1949. Rate of PJS has been expected to be very low i.e., 1 in 200,000 births $s^{4,5}$.

In gastrointestinal tract (GIT) PJS has been categorized into two main topographies, first one is mucocutaneous pigmentation and second one hamartomatous polyps. The most frequently involved positions of PJS in GIT are the jejunum, colorectal region, duodenum and stomach, in declining incidence ${ }^{6}$. In PJS patients, occurrence of tumours is
15 times higher than normal persons, whereas prevalence of malignant tumours is $20 \%{ }^{7}$.

Different tests are used for validation of PJS, among which genetic testing is more appropriate, used for identifying mutations that are responsible for PJS such as mutation in STK11 (serine/threonine-protein kinase 11 alias LKB1) gene that is in chromosome 19p13.3 and designated by Human Genome Organisation (HUGO) for LKB1, $1^{8,9}$. Non-steroidal anti-inflammatory drugs (NSAIDs) are most commonly used for treatment of PJS.

The indications for surgical treatments include patients with intestinal bleeding, intussuscep-tion, intestinal obstruction and malignant polyps established by endoscopic biopsy. For effective and appropriate management of polyps in PJS patients, surgical and endoscopic polypectomy is combinedly used ${ }^{10,11}$.

Still today, cases of small intestinal intussusception caused and combined with many altered types of polyps that are incidental found on laparotomy have rarely been reported.

\section{CONCLUSION}

Peutz-Jeghers syndrome (PJS) is extremely rare. Incidental findings of these sort of cases needs to be properly evaluated for genetic testing. We need more advancements in genetic, imaging and endoscopic techniques to be locally available so that screening and proper management should be timely and promptly.

\section{REFERENCES}

1. Tavusbay C, Acar T, Kar H, Atahan K, Kamer E. The patients with Peutz-Jeghers syndrome have a high risk of developing cancer. Turk J Surg. 2018; 34(2): 162-4. doi: 10.5152/turkjsurg.2017.3241

2. Sharma M, Singh R, Grover AS. Peutz-Jeghers syndrome with synchronous adenocarcinoma arising from ileal polyps. Indian J Surg. 2015; 77 (Suppl 1): 100-2. doi: 10.1007/s12262-014-1178-3.

3. Kopacova M, Tacheci I, Rejchrt S, Bures J. PeutzJeghers syndrome: diagnostic and therapeutic approach. World J Gastroenterol. 2009; 15(43): 5397-5408. doi:10.3748/ wjg.15.5397

4. Mărginean $\mathrm{CO}$, Meliţ LE, Patraulea $\mathrm{F}$, lunius $\mathrm{S}$, Mărginean MO. Early onset Peutz-Jeghers syndrome, the importance of appropriate diagnosis and follow-up: A Case Report. Medicine (Baltimore). 2019; 98(27): e16381. doi: 10.1097/ MD.0000000000016381

5. Cauchin E, Touchefeu Y, Matysiak-Budnik T. Hamartomatoustumors in the gastrointestinal tract. Gastrointest Tumors. 2015; 2(2): 65-74. doi: $10.1159 / 000437175$.

6. Duan SX, Wang GH, Zhong J, Ou WH, Fu MX, Wang FS, et al. Peutz-Jeghers syndrome with intermittent upper intestinal obstruction: a case report and review of the literature. Medicine 
(Baltimore). 2017; 96(17): e6538. doi: 10.1097/ MD.0000000000006538.

7. Wang R, Qi X, Liu X, Guo X. Peutz-Jeghers syndrome: four cases in one family. Intractable Rare Dis Res. 2016; 5(1): 42-3. doi: 10.5582/irdr. 2015.01036.

8. Wang Z, Wu B, Mosig RA, Chen Y, Ye F, Zhang $Y$, et al. STK11 domain XI mutations: candidate genetic drivers leading to the development of dysplastic polyps in Peutz-Jeghers syndrome. Hum Mutat. 2014; 35(7): 851-8. doi:10.1002/ humu. 22549
9. Poffenberger MC, Metcalfe-Roach A, Aguilar E, Chen J, Hsu BE, Wong AH, et al. LKB1 deficiency in $T$ cells promotes the development of gastrointestinal polyposis. Science. 2018; 361 (6400): 406-11. doi: 10.1126/science.aan3975.

10. Choudhury S, Das A, Misra P, Ray U, Sarangi S. Peutz-Jeghers syndrome: a circumventable emergency. Indian J Dermatol. 2018; 63(2): 16871. doi:10.4103/ijd.IJD_563_16

11. Wu M, Krishnamurthy K. StatPearls [Internet]. Peutz-Jeghers Syndrome. StatPearls publishing; Treasure Island (FL): Dec 17, 2019.

\begin{tabular}{|l|}
\multicolumn{1}{c|}{ AUTHOR AFFILIATION: } \\
Dr. Shahid Nazir (Correspondence Author) \\
Department of Surgery \\
Liaquat University of Medical and Health Sciences \\
(LUMHS), Jamshoro, Sindh-Pakistan. \\
Email: shahidnazir2702003@yahoo.com \\
Prof. Ambreen Munir \\
Department of Surgery \\
LUMHS, Jamshoro, Sindh-Pakistan. \\
Dr. Sehrish Sulman \\
Department of Surgery \\
LUMHS, Jamshoro, Sindh-Pakistan. \\
Dr. Qazi Waleed-u-Zaman \\
Department of Surgery \\
LUMHS, Jamshoro, Sindh-Pakistan. \\
Dr. Aisha Yar Muhammad \\
Department of Surgery \\
LUMHS, Jamshoro, Sindh-Pakistan. \\
\hline
\end{tabular}

